\title{
Enhanced Performance of Cellulose from Palm Oil Empty Fruit Bunch (EFB) via Acetylation and Silylation
}

\author{
Muhammad Johan Iskandar Zahari ${ }^{\mathrm{b}}$, Noraisah Mohd Jahi ${ }^{\mathrm{b}}$, Nurul Hanisah Mohd ${ }^{\mathrm{b}}$, Ishak \\ Ahmad $^{\text {a,b }}$, Azizah Baharum ${ }^{\text {a,b }}$, Azwan Mat Lazim ${ }^{\text {a,b }}$, Suria Ramli ${ }^{\text {a,b }}$ and Rizafizah \\ Othaman*a,b \\ a Polymer Research Centre (PORCE) \\ ${ }^{b}$ Faculty of Science and Technology, Universiti Kebangsaan Malaysia. \\ *Corresponding author: rizafizah@ukm.edu.my
}

\section{ABSTRACT}

Increase demand for palm oil production has indirectly increased waste and pollution. Empty fruit bunch (EFB), which is the major solid waste from this industry, has the potential to be further treated into valuable product. In this study, cellulose will be extracted from EFB through alkali treatment and acid hydrolysis treatment with a different approach and further modified via acetylation and silylation technique. The modified samples are to be utilized to reduce pollution due to palm oil mill effluent (POME) and carbon dioxide $\left(\mathrm{CO}_{2}\right)$ emission from the industry. The characterization of the extracted and modified cellulose was carried out using attenuated total reflectance-Fourier transform infrared (ATR-FTIR), thermogravimetric analysis (TGA) and scanning electron microscope (SEM). ATR-FTIR analysis revealed that the cellulose was successfully extracted from raw EFB and the cellulose-acetyl, nanocrystalline cellulose (NCC) and cellulose-2 has been successfully modified from the cellulose. TGA analysis shows that both modified cellulose have higher thermal stability compared to raw EFB and extracted cellulose. SEM morphology of the modified cellulose shows a higher surface area due to the wrinkled formation while the wax layer and cuticle pore has been diminished clearly. The modified sample gave a significant performance where cellulose-acetyl absorbed $98.5 \%$ of oil compared to unmodified cellulose-1 sample that only absorbed 5\% of oil from POME. NCC-AEAPDMS adsorbed physically and chemically $3.5 \mathrm{~cm}^{3} / \mathrm{g} \mathrm{CO}_{2}$ gas compared to NCC sample, which undergoes only physical adsorption with maximum capacity up to $2.4 \mathrm{~cm}^{3} / \mathrm{g}$. Thus, modification can enhanced the performance of cellulose for industrial applications.

Keyword: empty fruit bunch, cellulose, palm oil industry, acetylation, silylation 


\subsection{INTRODUCTION}

Palm oil industry is being leaded by Asian countries with the highest is Indonesia and second is Malaysia which cover more than $85 \%$ of world palm oil production (Iskandar et al. 2017). As for Malaysia itself, it has played a crucial role to drive the local economic scenario with more than $39 \%$ and $44 \%$ of global palm oil production and palm oil export (Iskandar et al. 2017). However, the drawbacks of this industry are the management of solid and liquid wastes that are still imprudent. Khatun et al. (2017) state that the palm oil industry is among the main contributor to the solid and liquid organic waste in Malaysia. A harvested palm oil can produce more than $70 \%$ of waste (Iskandar et al. 2017; Prasertsan \& Prasertsan 1996). Among the problems generated are waste from oil palm trunks (OPT), oil palm fronds (OPF), fresh fruit bunch (FFB), empty fruit bunch (EFB), together with palm oil mill effluent (POME), palm oil mill sludge (POMS) and $\mathrm{CO}_{2}$ emission (Singh et al. 2010; Abdullah and Sulaiman 2013).

$9 \%$ of the total waste was donated by the presence of empty fruit bunch (EFB). Empty fruit bunch (EFB) was formed after the fresh fruit bunch (FFB) was pressed to extract the palm oil. Interestingly, the so-called waste subsists compound like cellulose, hemicellulose and lignin which represent 40-65\%, 15-25\% and 12-20\% respectively (Fahma et al. 2010; Nazir et al. 2013) that can be utilized further to the various application from a different field. Usually, EFB will burn inside the boiler as a fuel-driven substance. Cellulose extraction from EFB involve several procedure such as alkali treatment (Nazir et al. 2013), sulfuric acid hydrolysis (Sheltami et al. 2012), formic acid (Johar et al. 2012), hydrogen peroxide (Havarty et al. 2012) and Soxhlet extraction (Nazir et al. 2013) to eliminate wax and resin embedded on EFB fibers.

A great attribute of cellulose is its hydrophilicity. The dense hydroxyl functional group inside the cellulose structure offers great affinity towards polar substance. The hydroxyl group will form a hydrogen bond between vicinal structures thus increasing its crystallinity. In addition, the novel properties of cellulose such as sustainable, biodegradable, good thermal stability and excellent modulus ( $\mathrm{Lu}$ et al. 2008; Thakur et al. 2013; Thakur et al. 2014) has provide wide application of cellulose such as in the pharmaceuticals industry, chemical feed, and papers (Kumar et al. 2002). There are several cellulose crystal structures endowed which depend solely on the 
arrangement hydrogen bond which is cellulose I, II, III and IV (KroonBatenburg \& Kroon, 1997). Chemical modification of cellulose has been widely employed to enhance the properties whilst increasing its potential in various applications.

Modification by acetylation and silylation has been widely conducted to replace to the hydroxyl group of cellulose into another functional group such as aminosilane and acetyl. The replacement of the hydroxyl group will subsequently alter the chemical properties of cellulose such as its wetting behavior, crystallinity, modulus and thermal stability (Rowell et al. 1992). Tserki et al. (2005) studied the effect of acetylation technique on wood and hemp. It was found out that there was a removal of a non-crystalline constituent on the fibers, which contribute to changes in topography and surface energy. On the other hand, the inclusion of amine through covalent bond creates a stable adsorption compared to amine impregnation (Yu et al. 2012). Lu et al. (2008) have successfully grafted aminosilane onto nanofibrilated cellulose, which has successfully increased its mechanical properties, and changes in the wetting behavior have been recorded.

In this work, cellulose was extracted from industrial EFB via combination of acid, alkali and bleaching treatment. Explanation in the first part, is related to the cellulose modified with acetic acid while for the second part, is the isolation NCC from extracted EFB cellulose prior to modification with aminosilane, AEAPDMS. The acetylated cellulose was aimed for oil absorption from palm oil mill effluent (POME) and the silylated NCC was tested for $\mathrm{CO}_{2}$ adsorption. The significant of the modification on the respective performance was discussed. The study ultimate goal is to utilize the samples in reducing the pollution effectively and economically using the zerowaste strategy for the palm-oil industry in achieving a cycle with zero-waste and zero-pollution. 


\subsection{MATERIALS AND METHOD}

\subsection{Materials}

Empty fruit bunch (EFB) with was obtained from Szetech Engineering Sdn. Bhd. Sodium hydroxide, Acetone, Toluene and Acetic Acid with 97\%, 99.5\%, 99.8\% and 99.8\% of purity respectively were from SYSTERM, Malaysia while Sodium Chlorite $\left(\mathrm{NaClO}_{2}\right)$, Anhydrous Acetic Acid and Pyridine with $80.0 \%, 99.0 \%$ and $99.8 \%$ purity respectively were from Sigma-Aldrich, Malaysia. Sulfuric acid with $95 \%$ purity was from J.T. Baker.

\subsection{Methods}

\subsubsection{Sample Preparation}

The EFB was rinsed with distilled water to eliminate dust prior to drying in an oven for 24 hours at $105^{\circ} \mathrm{C}$. The dried EFB was cut into smaller pieces using fiber grinders. Size range of 125 - 250 $\mu \mathrm{m}$ was obtained and separated by using a sieve shaker.

\subsubsection{Cellulose Extraction and Modification}

(a) The EFB was immersed inside 2:1 (v/v) ethanol/toluene solution for $6-8$ hours at $100{ }^{\circ} \mathrm{C}$ using Soxhlet extraction method. Next, $10 \%(w / v)$ of $\mathrm{NaOH}$ was used to obliterate the hemicellulose component from the pre-treated EFB using a reflux method for 3 hours at $70{ }^{\circ} \mathrm{C}$. Lastly, a bleaching treatment was prepared by mixing $1.7 \%(\mathrm{w} / \mathrm{v})$ of $\mathrm{NaCIO}_{2}$ inside an acetate buffer solution ( $27 \mathrm{~g}$ of $\mathrm{NaOH}+75 \mathrm{ml}$ acetic acid $+1 \mathrm{~L}$ of distilled water). The EFB is soaked inside the solvent for 4 hours at 80 to $90{ }^{\circ} \mathrm{C}$. The treated fibers (cellulose-1) were dried in the oven at $105^{\circ} \mathrm{C}$ until reached a constant mass.

Subsequently, the cellulose was treated with an anhydrous acetic acid reagent and pyridine reagent (catalyst) adapting a reflux method under atmospheric pressure for 1 hour. The ratio of cellulose: $\left(\mathrm{CH}_{3} \mathrm{CO}\right)_{2} \mathrm{O}$ used was 1:40 (w/v) while pyridine reagent catalyst used was $2 \%$ from the mass of cellulose used. The cellulose (cellulose-acetyl) was rinsed with $2: 1 \mathrm{wt} / \mathrm{wt}$ 
acetone-ethanol solution for 6 hours. The mechanism for the reaction between cellulose-1 with acetic acid is displayed in Figure 1.
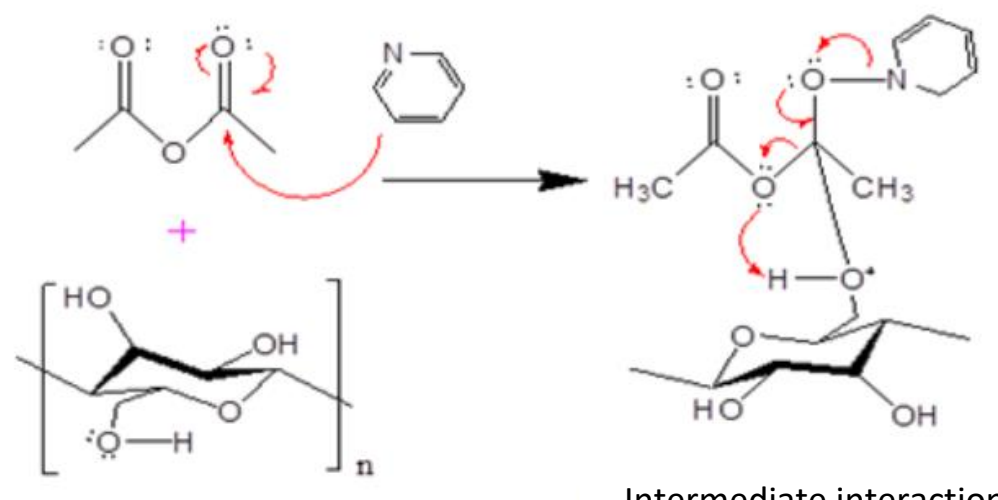

Cellulose-1

Intermediate interaction

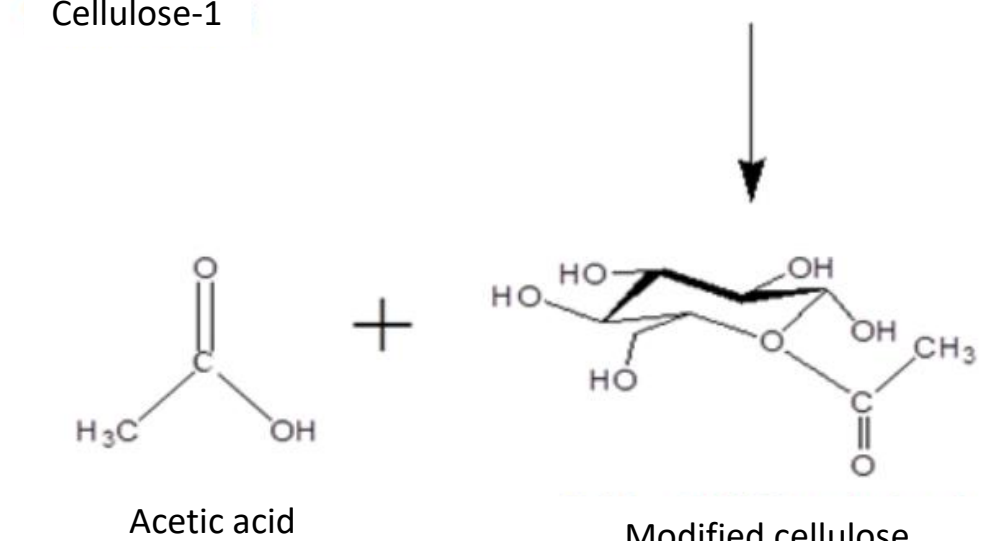

Figure 1 Interaction mechanism between cellulose and acetic acid (Bello-Perez et al. 2010)

(b) The EFB was immersed inside of 2:1 (v/v) toluene-ethanol solution for 6 hours using Soxhlet extraction method. Then, $4 \%(\mathrm{w} / \mathrm{v})$ of $\mathrm{NaOH}$ solution was used to reflux the pre-treated EFB under mechanical stirring for 3 hours at $80-90{ }^{\circ} \mathrm{C}$. This process was repeated for three times. Lastly, the fiber undergoes a bleaching process. $1.7 \%(\mathrm{w} / \mathrm{v}) \mathrm{NaCIO}_{2}$ solution and a buffer solution $(27 \mathrm{~g} \mathrm{NaOH}+75 \mathrm{ml}$ glacial acetic acid $+500 \mathrm{ml}$ distilled water) were prepared as a reflux solution for the fiber. It was repeated for 4 times under mechanical stirring for 4 hours at $80-90{ }^{\circ} \mathrm{C}$. The prepared fiber (cellulose-2) was rinsed and dried at room temperature. 
NCC was obtained from extracted EFB cellulose via acid hydrolysis method. It was isolated using $60 \%$ (v/v) $\mathrm{H}_{2} \mathrm{SO}_{4}$ solution under constant mechanical stirring for 45 minutes at $45{ }^{\circ} \mathrm{C}$. The NCC was centrifuged for 10 minutes at $10{ }^{\circ} \mathrm{C}$, dialysed until a constant $\mathrm{pH}$ was reached, ultrasonicated to disentangle the nanocrystal and lastly stored in the freezer. The NCC was modified using AEAPDMS (1:3) in 80:20 (v/v) of water/ethanol for 3 hours at $60{ }^{\circ} \mathrm{C}$ and labeled as NCC-AEAPDMS. The schematic of the reaction between NCC and AEAPDMS is displayed in Figure 2.
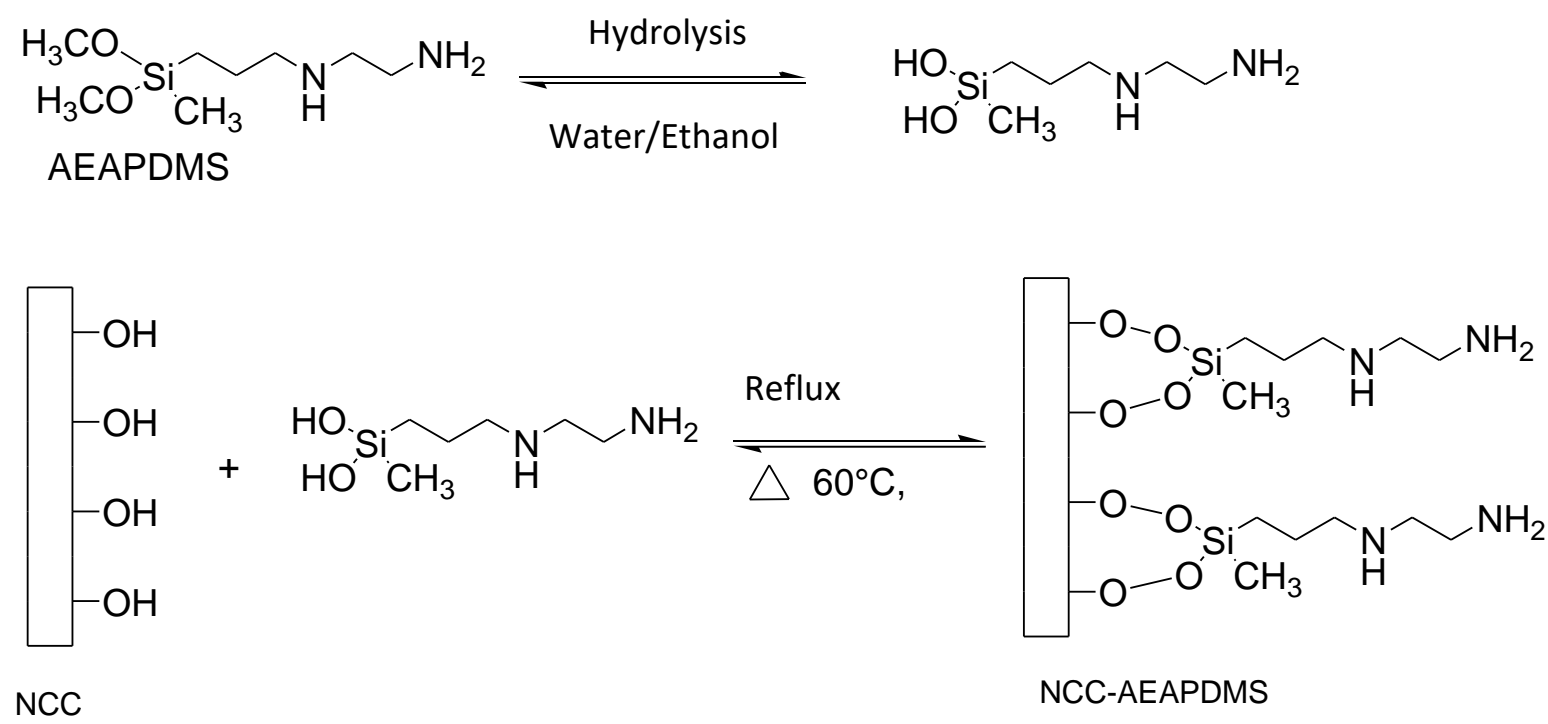

Figure 2 Schematic reaction between NCC and AEAPDMS

\subsection{Cellulose Characterization}

\subsubsection{Fourier Transform Infra-Red (FTIR)}

Infrared spectroscopy is used to determine the functional groups present in the EFB, cellulose-1, cellulose-2, NCC, cellulose-acetyl and NCC-AEADPMS. This infrared spectroscopic analysis was carried out using Fourier transform infrared (FTIR) Perkin Elmer model with a spectral range of 650 to $4000 \mathrm{~cm}^{-1}$. 


\subsubsection{Thermogravimetric Analysis (TGA) and Differential Thermal Gravimetric (DTG)}

Dynamic thermogravimetric analysis (TGA) was performed by using a Mettler Toledo thermogravimetric analyzer with TGA/SDTA851e model. 5-10 mg of sample at room temperature $\left(25^{\circ} \mathrm{C}\right.$ ) will be heated until the temperature reaches $600{ }^{\circ} \mathrm{C}$ with a heating rate of $10^{\circ} \mathrm{C} \cdot \min ^{-1}$ under nitrogen atmosphere. The thermogram obtained from this analysis shows the remaining weight during combustion (TGA curve) and its derivative (DTG curve) as a function of the analyzed temperature.

\subsubsection{Scanning Electron Microscopy (SEM)}

In this work, two models of SEM were used to observe the images of raw EFB, cellulose, NCC, cellulose-acetyl and NCC-AEAPDMS.

MERLIN's model of electron scanning electron microscope (SEM) by ZEISS brand was used to analyze the surface morphology of EFB, and cellulose-acetyl. Each sample was prepared in a solid form and cut in small size of $1 \mathrm{~mm}$ x $1 \mathrm{~mm}$ dimension. The sample was electroplated with a gold layer inside a coating chamber (Sputter model SC 500) with a thickness of 0.01 to $0.1 \mu \mathrm{m}$.

While field scanning electron microscope (FESEM) with brand Zeiss Supra model 55VP SEM has been used with a $15 \mathrm{KV}$ acceleration to obtain an image of NCC and NCC-AEAPDMS. Both of the samples have been prepared in the form of powder, which obtained after drying in a freeze drier.

\subsubsection{Application}

After the successful modification of the cellulosic sample, the adsorption performance of both samples was examined. Comparison was made to evaluate the performance before and after modification.

Oil absorption test from actual palm oil mill effluent (POME) was utilized to monitor the absorption for cellulose- 1 and cellulose-acetyl sample. The absorption was done according to 
column method as shown in figure $3.10 \mathrm{~g}$ of cellulose-1 and cellulose-acetyl sample was used separately and was compressed inside the column.

While $\mathrm{CO}_{2}$ adsorption test was done to NCC and NCC-AEAPDMS using Micromeritics ASAP 2010 instrument. $0.1 \mathrm{~g}$ of NCC sample was put inside glass tube and undergo degas process using $\mathrm{N}_{2}$ gas at $80^{\circ} \mathrm{C}$ for 24 hour. Later, $\mathrm{CO}_{2}$ gas was replaced at $25^{\circ} \mathrm{C}$. The adsorption isotherm is recorded until 1 atm relative pressure was reached. Experiment was repeated using NCCAEAPDMS.

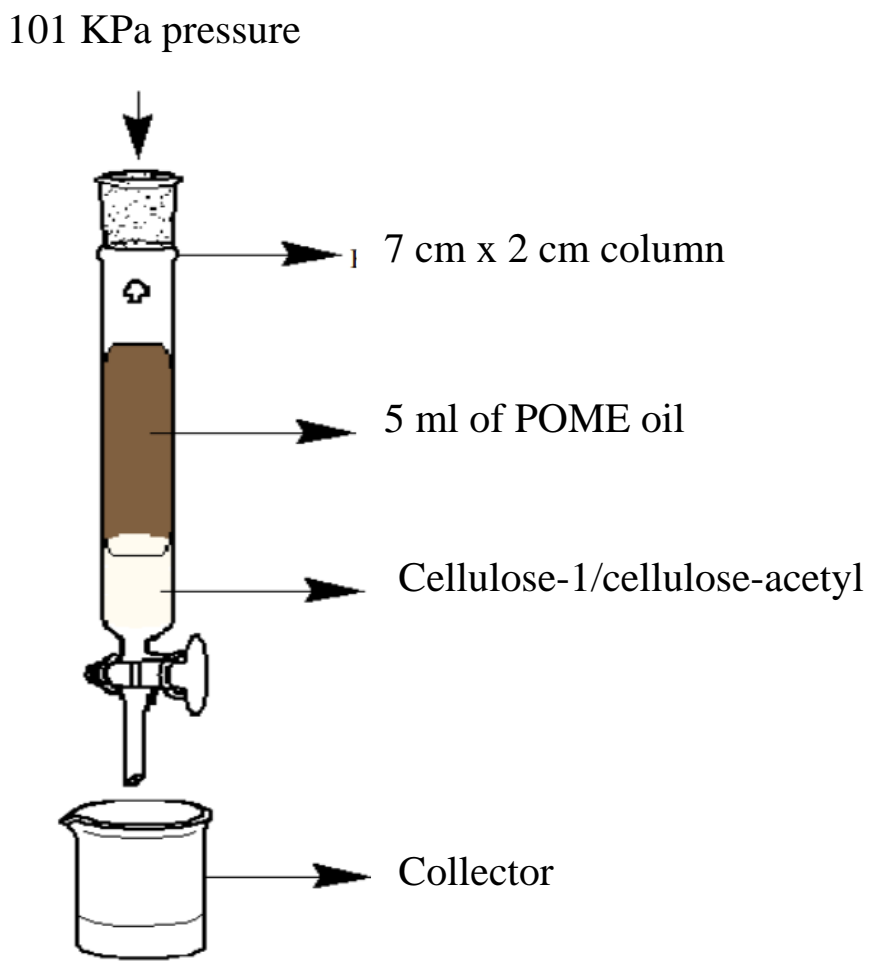

Figure 3 Column for oil absorption test 


\subsection{RESULTS AND DISCUSSION}

\subsection{Fourier Transform Infra-Red (FTIR)}

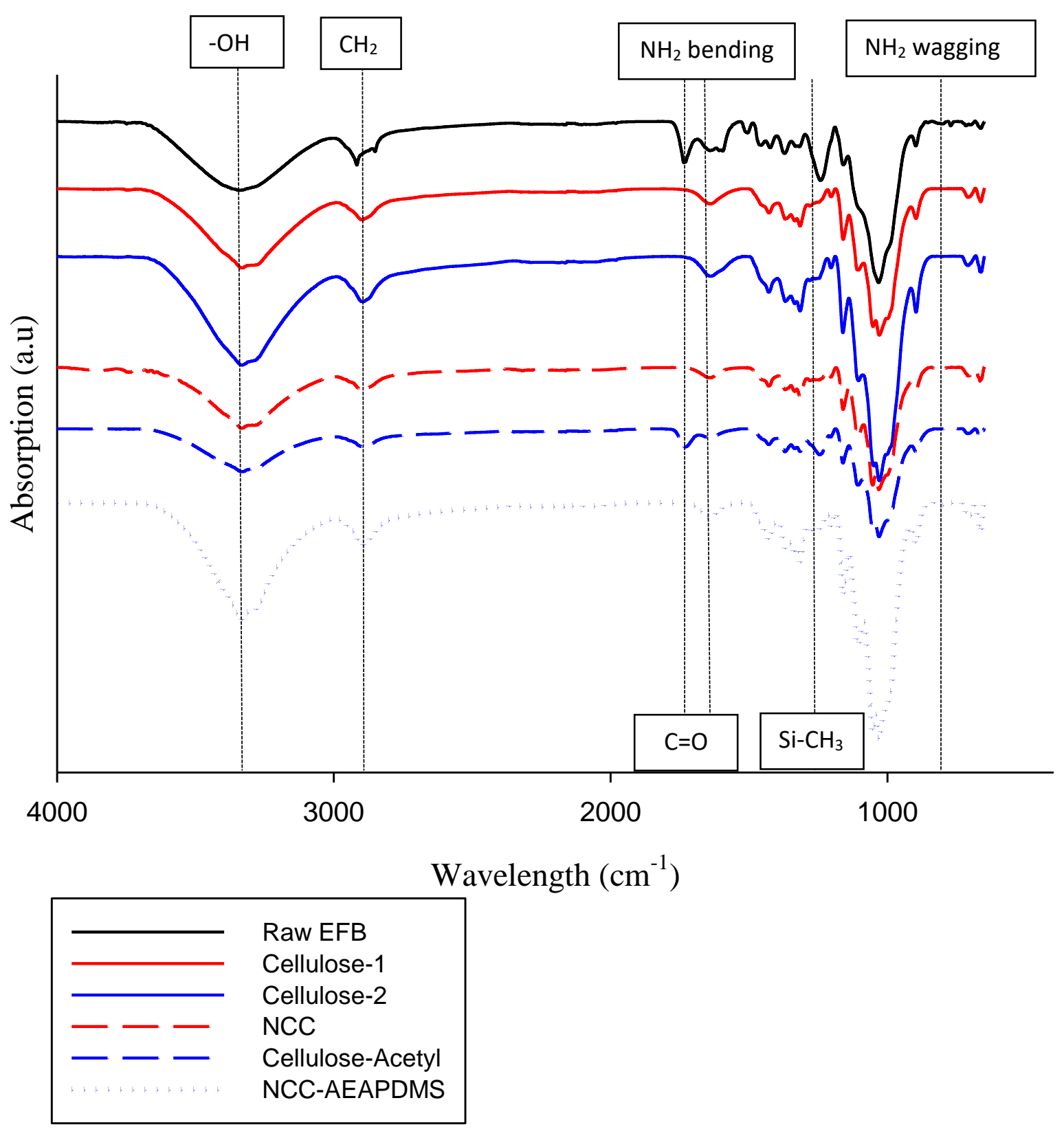

Figure 4 FTIR spectra of EFB, Cellulose-1, Cellulose-2, NCC, Cellulose-acetyl and NCCAEAPDMS. 
The FTIR spectra of EFB, cellulose-1, cellulose-2, NCC, cellulose-acetyl and celluloseAEADPMS as depicted in Figure 4. A common peak for cellulose will be visible in the range of $3300-3450 \mathrm{~cm}^{-1}$, which indicate the presence of $-\mathrm{OH}$ functional group, and $2900-2990 \mathrm{~cm}^{-1}$ of - $\mathrm{CH}$ vibration can be observed in all the samples (Wang et al. 2012; Fan et al. 2013; Ngadi \& Lani 2014). For raw EFB, the visible spectrum at the wavelength of $1729 \mathrm{~cm}^{-1}$ corresponds to the acetyl group which usually present in ester hemicellulose structure or p-coumaric carbonyl ester lignin unit (Walia et al. 2009; Abdullah et al. 2010; Draman et al. 2013).

After the acetylation process of cellulose-1, the presence of a new band at the wavelength of 1243 $\mathrm{cm}^{-1}$ which corresponds to the formation of $\mathrm{C}-\mathrm{O}$ and $\mathrm{C}=\mathrm{O}$ functional group from ester bond is observed. It is believed that the appearance of $\mathrm{C}-\mathrm{O}$ and $\mathrm{C}=\mathrm{O}$ functional groups are originated from the anhydrous acetic acid used during the acetylation process. In addition, due to the presence of $\mathrm{C}-\mathrm{O}-\mathrm{C}$ aryl-alkyl ether in raw EFB, absorbance at the wavelength of $1240 \mathrm{~cm}^{-1}$ was observed. After the cellulose extraction process, the peak has diminished indicating that the lignin has been successfully removed from the cellulose sample (Sheltami et al. 2012). Cellulose-1 and cellulose2 show distinct peaks intensity due to the different approach to extract them. Apart from that, absorption peak between $1420-1430 \mathrm{~cm}^{-1}$ and $1330-1380 \mathrm{~cm}^{-1}$ are visible due to the presence of $\mathrm{CH}_{2}$ symmetrical bending, $\mathrm{CH}$ vibration and $\mathrm{CO}$ aromatic ring group in polysaccharides (Jonoobi et al. 2009; Kargarzadeh et al. 2012). The peak between $890-900 \mathrm{~cm}^{-1}$ correspond to the $\beta$-glycosidic chain which visible in all the samples (Nazir et al. 2013).

Further treatment of cellulose- 1 and cellulose- 2 has subsequently changed some of the absorption band. For cellulose-acetyl, which is derived from cellulose-1, it can be observed that the peak intensity at $3300-3450 \mathrm{~cm}^{-1}$ for this sample has significantly reduced due to the substitution from -OH functional group to acetyl functional group. On the other hand, the crystallinity behavior of NCC sample can be detected from the absorption peak around in the range of $1280 \mathrm{~cm}^{-1}$ and 1204 $\mathrm{cm}^{-1}$ which correspond $-\mathrm{CH}$ and $-\mathrm{OH}$ bending respectively (Fahma et al. 2010; Hulleman et al. 1994). From the FTIR spectrum, it can be assured that all the lignin have been successfully removed from the EFB while incrementing of absorption peak intensity at $1280 \mathrm{~cm}^{-1}$ which proportional to the increment in crystallinity area. 
Modification of NCC to cellulose-AEAPDMS has emerged several new peaks. This is caused by the functional group presence in AEAPDMS sample which contributes to new absorption spectrum at $1600 \mathrm{~cm}^{-1}$ and $768 \mathrm{~cm}^{-1}$ which correspond to $\mathrm{NH}_{2}$ bending and vibration respectively. Abdelmouleh et al. (2004) and Zhao et al. (2011) also stated that the new peak is due to the bonding of $\mathrm{NH}_{2}$ hydrogen to $-\mathrm{OH}$ functional group for both silanol and cellulose. It can be proved that $\mathrm{NH}_{2}$ bending peak at NCC has shifted to after the modification from 1559 to $1549 \mathrm{~cm}^{-1}$. Rachini et al (2012) reported that the absorption peak at $1030 \mathrm{~cm}^{-1}, 1055 \mathrm{~cm}^{-1}, 1110 \mathrm{~cm}^{-1}$ and $1146 \mathrm{~cm}^{-1}$ correspond to $\mathrm{Si}-\mathrm{O}-\mathrm{Si}$ and $\mathrm{Si}-\mathrm{O}-\mathrm{C}$ which indicate that AEAPDSM has been successfully modified on NCC. 


\subsection{Thermogravimetric Analysis (TGA) and Differential Thermal Gravimetric (DTG)}

Figure 5 displays the TGA and DTG thermogram of EFB, cellulose-1, cellulose-2, NCC, celluloseacetyl and NCC-AEADPMS. Cellulose is a hygroscopic compound, thus an increment in heat until $100{ }^{\circ} \mathrm{C}$ has caused the evaporation of water that can be observed by a small curve in the thermogram for all of the samples. In addition, a small endothermic curve between $75-100{ }^{\circ} \mathrm{C}$ can be observed that indicate the heat entrance into the entire sample.

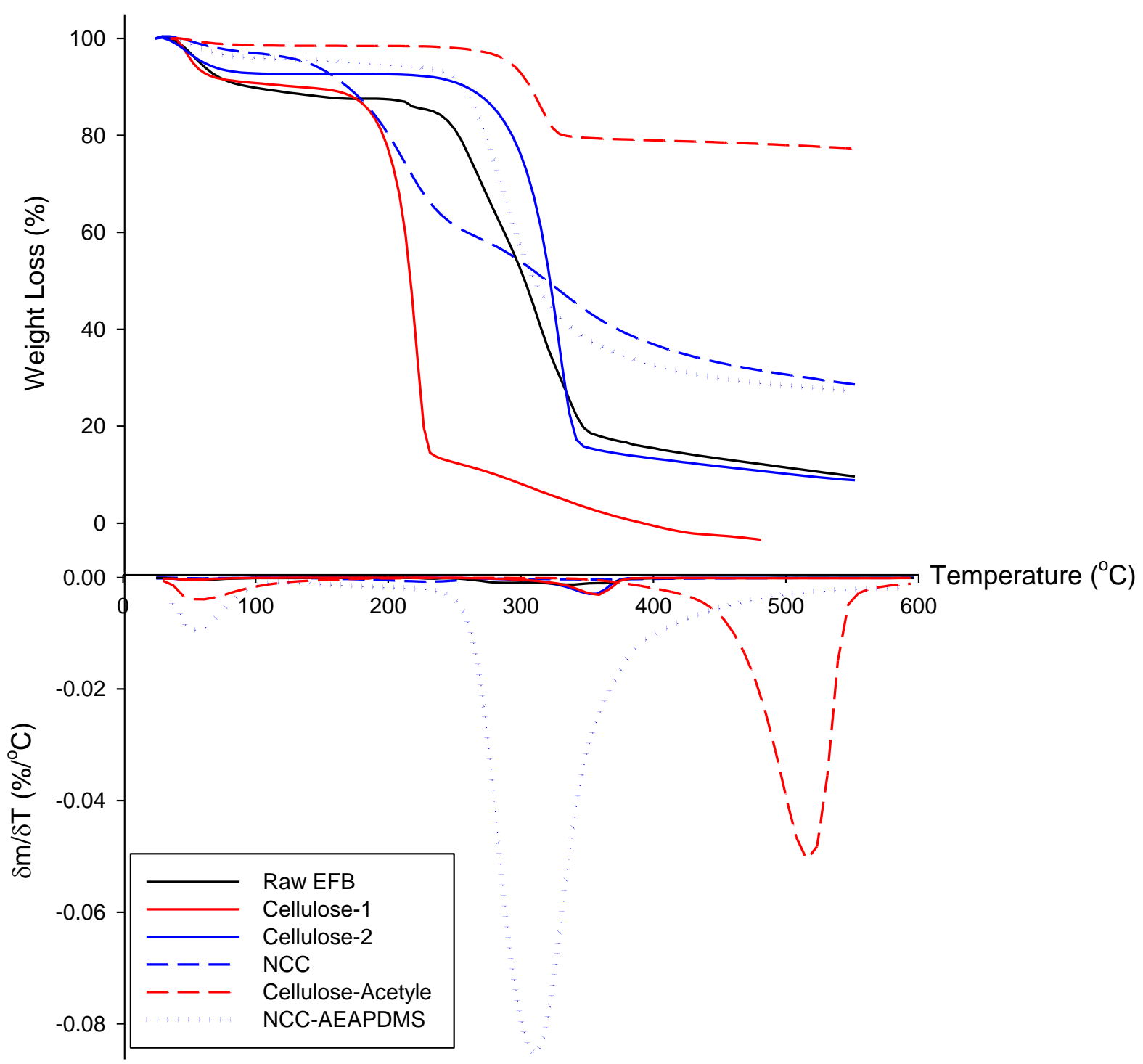

Figure 5 TGA and DTG of EFB, cellulose-1, cellulose-2, NCC, cellulose-acetyl and NCC- 
Cellulose that undergoes different extraction process shows different thermal behavior as cellulose-2 is much more stable compared to cellulose-1. Different method of extraction will affect the purity of cellulose produced, which related to the different content of hemicellulose, lignin and pectin. Raw EFB starts to decompose at $260^{\circ} \mathrm{C}$ while cellulose- 1 and 2 starts to decompose at $200{ }^{\circ} \mathrm{C}$ and $320^{\circ} \mathrm{C}$ respectively. Same decomposition pattern at different temperature has been shown by the raw EFB and cellulose before modification.

Compared to the cellulose-1, the cellulose-acetyl shows a smaller loss from the curve due to the presence of acetyl group and affinity towards water compared to hydroxyl groups. It displays a lower affinity towards water and moisture after the acetylation process (Jonoobi et al. 2010). This is due to the presence of the acetyl group at the backbone of the structure, which promoted a covalent bond between them. Moreover, the residue left for both samples display a tremendous different before and after acetylation process thus making the cellulose-acetyl has higher thermal stability. A different pattern can be observed by NCC and NCC-AEAPDMS thermogram since the post-process after the extraction has significantly modified the crystallinity and molecular structure of the cellulose.

NCC shows two decomposition peaks, which at $120^{\circ} \mathrm{C}$ related to the presence of sulfate at amorphous region and at $250{ }^{\circ} \mathrm{C}$ related to the crystal region breakdown. NCC shows a lower thermal stability compared to raw EFB and cellulose-2. After modification, the properties of NCCAEAPDMS resemble unmodified cellulose properties with an only one decomposition peak. Despite that, the thermal stability has slightly increased due to the presence of aminosilane on cellulose structure. The same trend has also reported by Wang et al. (2011) and Hahn et al. (2016). The highest decomposition of the all the sample occurred at a range between $180-380^{\circ} \mathrm{C}$. 


\subsection{Scanning Electron Microscopy (SEM)}

Figure 6 shows the SEM image of raw EFB, cellulose-acetyl, NCC and NCC-AEADPMS. The morphology of EFB with cellulose-acetyl, NCC and NCC-AEAPDMS show a significant difference. Raw EFB (Fig. 6a) shows that the fibers still bound to each other with the presence of cuticle pores on the surface and slightly smooth and flat surface due to the presence of wax which coat the fibers surface. After the extraction and modification (Fig. 6b-d), the cuticle and wax layer are being removed from fibers surface, which contributes to a more wrinkled and clearer surface and smaller diameter fibers (Feria et al. 2011; Wang et al. 2012; Draman et al. 2013). It is proven that most of the hemicellulose, lignin and pectin has been removed after the extraction and modification.

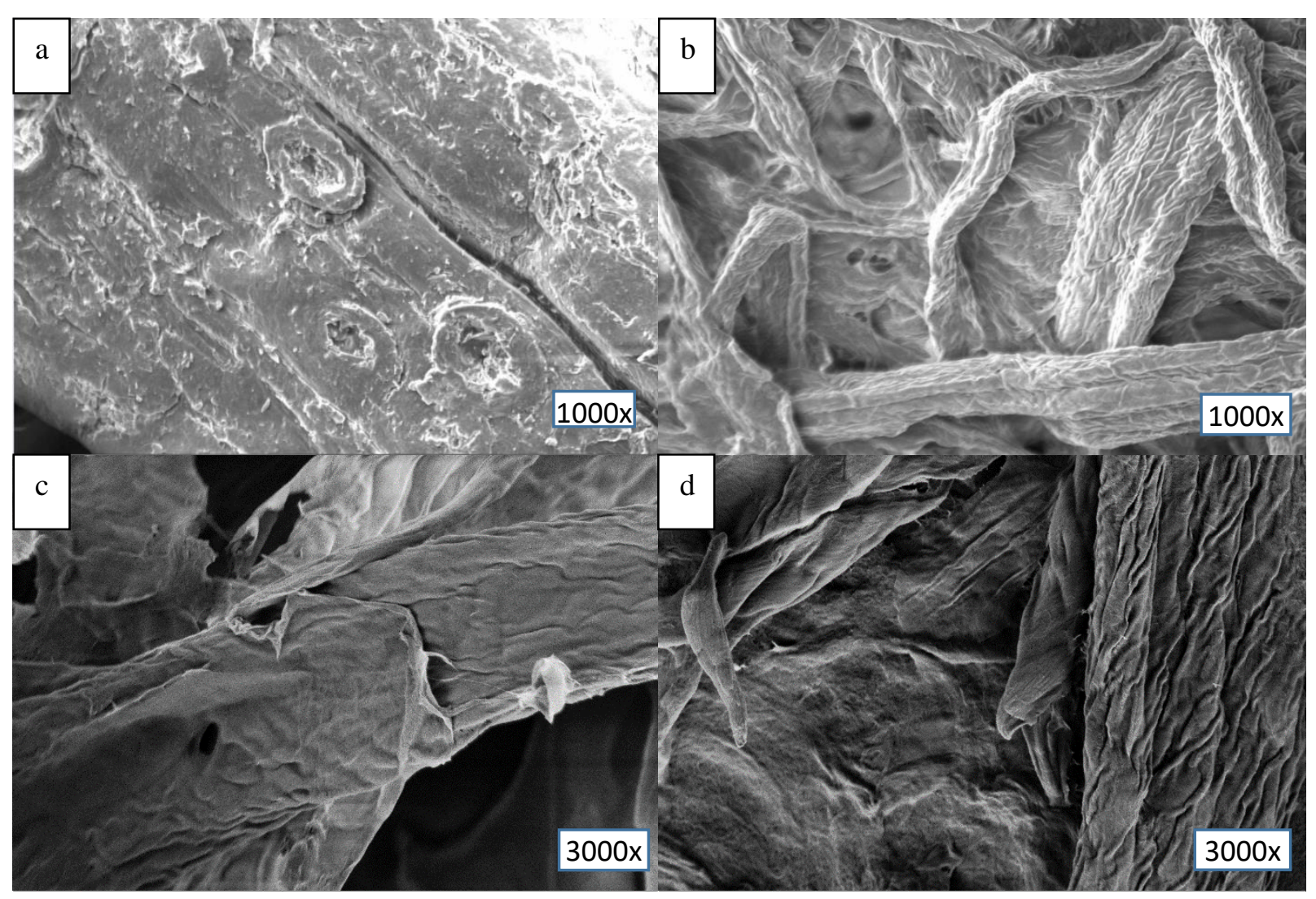

Figure 6 Morphology of (a) Raw EFB, (b) Cellulose-acetyl, (c) NCC and (d) NCC-AEAPDMS 
As stated by Sheltami et al. (2012), the removal of hemicellulose, lignin and pectin can be achieved with only $2 \%$ of $\mathrm{NaOH}$. However, some of the lignin will still remain in the fibers due to the presence of ester bond between lignin and cellulose group, which binds the EFB cellulose together. Apart from that, the lignin decomposition treatment will expose a hydroxyl, carbonyl and carboxylic functional group (Cherian et al. 2010). After the acetylation process, the fibers swelled. This is due to the usage of pyridine catalyst to facilitate the penetration of anhydrous acetic to the fibers. As a result, a rougher and grooves surface has been yielded which indirectly provide a larger surface area for any reaction to occur. Besides, the higher temperature during acetylation process is used to assist the substitution of acetyl molecule to the $\mathrm{OH}$ - base in the fibers.

Moreover, NCC (Fig. 6c) shows a much smoother surface compared to cellulose-acetyl and NCCAEAPDMS. NCC resembles cellulose structure without the amorphous region, thus the smooth surface of NCC supposedly resembles raw EFB structure without a wax layer, hemicellulose, pectin and lignin (Thakur et al. 2014). Further modification of NCC with aminosilane has endowed a rougher surface. This is due to the presence of aminosilane that bound to NCC surface. The same phenomenon has been reported by Kalia et al. (2014) where the surface of NFC becomes rougher after modification.

\subsection{Application}

The performance of cellulose-acetyl sample for oil absorption from POME was done using the setup in Figure 3. As the result, cellulose-acetyl managed to absorb $98.5 \%$ of oil compared to cellulose-1 sample that only absorbed $5 \%$ of oil. A distinct result is caused by the successful acetylation of cellulose-1. This is due to the presence of acetyl group compared to hydrogen group on the cellulose backbone which makes the cellulose-acetyl became hydrophobic and favorable to oil adsorption.

On the other hand, the silylated nanocellulose, NCC-AEAPDMS, was applied for $\mathrm{CO}_{2}$ adsorption test. Both of the physical and chemical adsorptions has occurred on NCC-AEAPDMS sample with adsorption capacity of $3.3 \mathrm{~cm}^{3} / \mathrm{g}$ compared to NCC sample which undergoes only physical adsorption with maximum capacity up to $2.4 \mathrm{~cm}^{3} / \mathrm{g}$. Physical adsorption occurred at high pressure 
and low temperature while chemical adsorption is vice versa ( $\mathrm{Yu}$ et al. 2012). The increase in adsorption capacity according to Arenillas et al. (2005) is due to the presence of $\mathrm{N}$ functional group with basic property and interact with $\mathrm{CO}_{2}$ with acidic property that explain the occurrence of chemical adsorption. In addition, the adsorption mod for $\mathrm{CO}_{2}$ is relatively depending on the properties of an amine group and the distance between the aminosilane (Hahn et al. 2016; Yu et al. 2012). Figure 7 shows the combination graph for the enhancement performance of the modified cellulose samples. The significant enhancement of the performance was due to the modification of the cellulose should be done according to the purpose of the application.

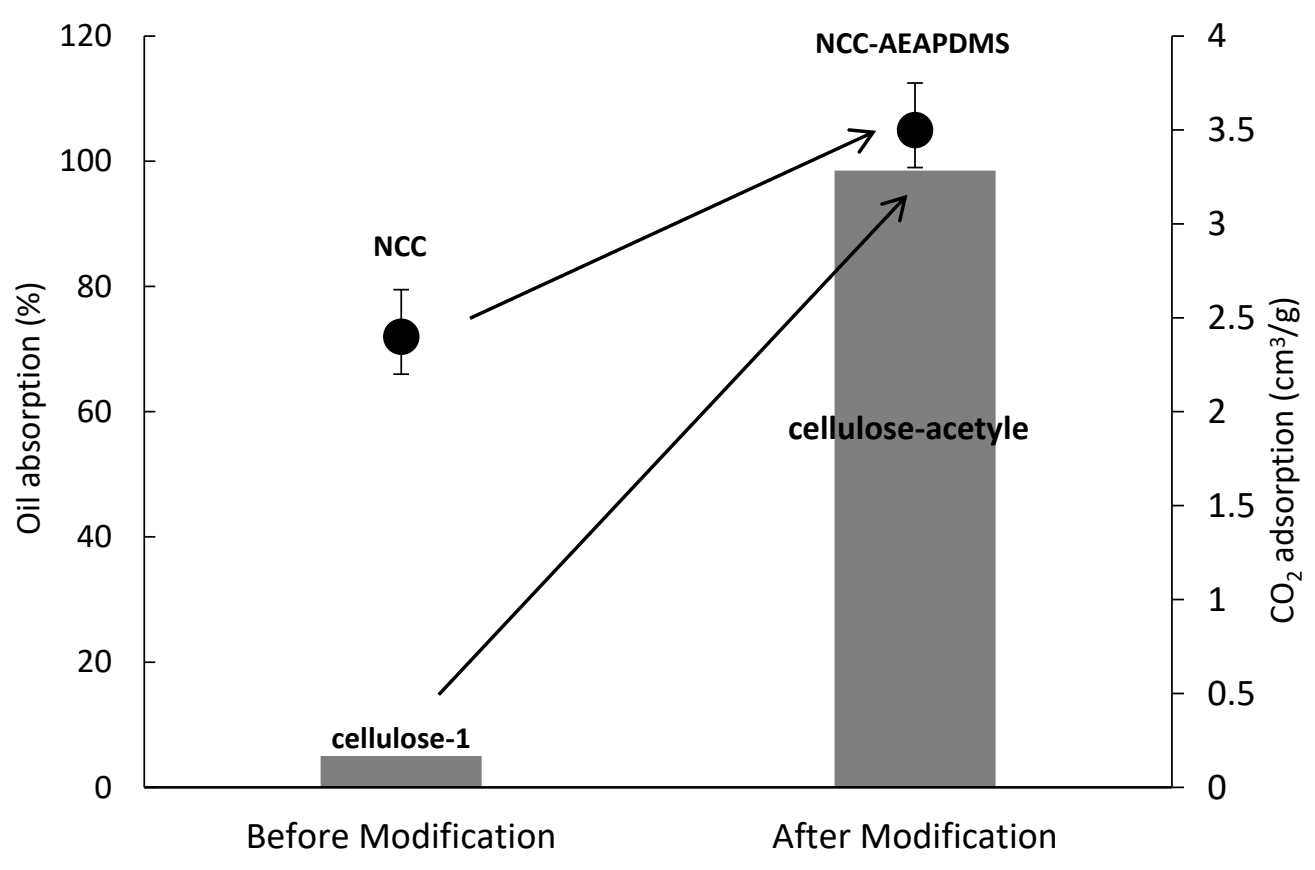

Figure 7 Comparison of absorption and adsorption for cellulose and modified cellulose sample.

\section{Conclusion}

In this work, we have presented that cellulose extracted from oil palm empty fruit bunch (EFB). Then, the acetylation and silylation modification have been successfully done on the cellulose sample. FTIR spectrum shows that the $-\mathrm{OH}$ intensity peak has reduced after acetylation process on cellulose- 1 and the presence of $\mathrm{NH}_{2}$ peak after further treatment of cellulose- 2 into NCC, indicating crystallinity of NCC. Modification of NCC with AEAPDMS has form Si-O-Si and Si- 
O-C peak that explains the successful modification of AEAPDMS on NCC sample. Apart from that, the thermal stability for both modified cellulose has tremendously increased since there is an interaction of cellulose with both acetyl and AEAPDMS. SEM images show that all the wax layer and cuticle pore has been removed and modification on the sample has increased the surface area and decrease the smoothness of the sample. The absorption and adsorption for both of the modified cellulose has demostrate a tremendous increment.

\section{Acknowledgement}

The authors would like to thank research grants ST-2017-008 dan GUP-2012-076, Universiti Kebangsaan Malaysia, Polymer Research Center (PORCE), and Center for Research Instrumentation and Management (CRIM).

\section{Reference}

1. Abdelmouleh, M., Boufi, S., Belgacem, M. N., Duarte, A. P., Ben Salah, A. \& Gandini, A. 2004. Modification of cellulosic fibres with functionalised silanes: development of surface properties. International Journal of Adhesion and Adhesives 24(1): 43-54.

2. Abdullah, M., Rahmah, A. U. \& Man, Z. 2010. Physicochemical and sorption characteristics of Malaysian Ceiba pentandra (L.) Gaertn. as a natural oil sorbent. Journal of Hazardous Materials 177(1): 683-691.

3. Abdullah, N. \& Sulaiman, F. 2013. The Oil Palm Wastes in Malaysia. Biomass Now Sustainable Growth and Use. 75-100. ISBN 978-953-51-1105-4.

4. Arenillas, A., Rubiera, F., Parra, J., Ania, C. \& Pis, J. 2005. Surface modification of low cost carbons for their application in the environmental protection. Applied Surface Science 252(3): 619-624

5. Bello-Pérez, L. A., Agama-Acevedo, E., Zamudio-Flores, P. B., Mendez-Montealvo, G. \& Rodriguez-Ambriz, S. L. 2010. Effect of low and high acetylation degree in the morphological, physicochemical and structural characteristics of barley starch. LWTFood Science and Technology 43(9): 1434-1440. 
6. Cherian, B. M., Leão, A. L., de Souza, S. F., Thomas, S., Pothan, L. A. \& Kottaisamy, M. 2010. Isolation of nanocellulose from pineapple leaf fibres by steam explosion. Carbohydrate Polymers 81(3): 720-725.

7. Draman, S. F. S., Daik, R., Latif, F. A. \& El-Sheikh, S. M. 2013. Characterization and thermal decomposition kinetics of kapok (Ceiba pentandra L.)-based cellulose. BioResources 9(1): 8-23.

8. Fahma, F., Iwamoto, S., Hori, N., Iwata, T. \& Takemura, A. 2010. Isolation, preparation, and characterization of nanofibers from oil palm empty-fruit-bunch (OPEFB). Cellulose-17(5): 977-985.

9. Fan, G., Wang, M., Liao, C., Fang, T., Li, J. \& Zhou, R. 2013. Isolation of cellulose from rice straw and its conversion into cellulose acetate catalyzed by phosphotungstic acid. Carbohydrate polymers 94(1): 71-76

10. Feria, M. J., García, J. C., Pérez, A., Gomide, J. L., Colodette, J. L. \& López, F. 2011. Process optimization in kraft pulping, bleaching, and beating of leucaena diversifolia. BioResources 7(1): 0283-0297.

11. Hahn, M. W., Jelic, J., Berger, E., Reuter, K., Jentys, A. \& Lercher, J. A. 2016. Role of Amine Functionality for $\mathrm{CO} 2$ Chemisorption on Silica. The Journal of Physical Chemistry B 120(8): 1988-1995.

12. Havarty, D., Dussan, K., Piterina, A. V., Leahy, J. J. \& Hayes, M. H. B. 2012. Autothermal, single-stage, performic acid pretreatment of Miscanthus $x$ giganteus for the rapid fractionation of its biomass components into a lignin/hemicellulose-rich liquor and a cellulase-digestible pulp. Bioresource technology 109: 173-177.

13. Hulleman, S. H. D., Van Hazendonk, J. M. \& Van Dam, J. E. G. 1994. Determination of crystallinity in native cellulose from higher plants with diffuse reflectance Fourier transform infrared spectroscopy. Carbohydrate Research 261(1): 163172.

14. Iskandar, M. J., Baharum, A., Anuar, F. H. \& Othaman, R. 2017. Palm oil industry in South East Asia and the effluent treatment technology-A review. Environmental Technology \& Innovation 9: 169-185.

15. Johar, N., Ahmad, I. \& Dufresne, A. 2012. Extraction, preparation and characterization of cellulose fibres and nanocrystals from rice husk. Industrial Crops and Products 37(1): 93-99. 
16. Jonoobi, M., Niska, K. O., Harun, J. \& Misra, M. 2009. Chemical composition, crystallinity, and thermal degradation of bleached and unbleached kenaf bast (Hibiscus cannabinus) pulp and nanofibers. BioResources 4(2): 626-639.

17. Jonoobi, M., Harun, J., Mathew, A. P., Hussein, M. Z. B. \& Oksman, K. 2010. Preparation of cellulose nanofibers with hydrophobic surface characteristics. Cellulose-17(2): 299-307

18. Kalia, S., Boufi, S., Celli, A. \& Kango, S. 2014. Nanofibrillated cellulose: surface modification and potential applications. Colloid and Polymer Science 292(1): 5-31.

19. Kargarzadeh, H., Ahmad, I., Abdullah, I., Dufresne, A., Zainudin, S. Y. \& Sheltami, R. M. 2012. Effects of hydrolysis conditions on the morphology, crystallinity, and thermal stability of cellulose nanocrystals extracted from kenaf bast fibers. Cellulose-19(3): 855-866.

20. Khatun, R., Reza, M. I. H., Moniruzzaman, M. \& Yaakob, Z. 2017. Sustainable oil palm industry: The possibilities. Renewable and Sustainable Energy Reviews 76: 608-619.

21. KroonBatenburg, L. M. J. \& Kroon, J. 1997. The crystal and molecular structures of cellulose I and II. Glycoconjugate J. 14: 677-690.

22. Kumar, V., Reus-Medina, M. D. L., \& Yang, D. 2002. Preparation, characterization, and tableting properties of a new cellulose-based pharmaceutical aid. International Journal of Pharmaceutics 235: 129-140.

23. Lu, J., Askeland, P., \& Drzal, L. T. 2008. Surface modification of microfibrillated cellulose for epoxy composite applications. Polymer 49: 1285-1296.

24. Nazir, M. S., Wahjoedi, B. A., Yussof, A. W. \& Abdullah, M. A. 2013. Eco-friendly extraction and characterization of cellulose from oil palm empty fruit bunches. BioResources $8(2)$.

25. Ngadi, N. \& Lani, N. S. 2014. Extraction and Characterization of Cellulose from Empty Fruit Bunch (EFB) Fiber. Jurnal Teknologi 68(5):35-39.

26. Prasertsan, S. \& Prasertsan P. 1996. Biomass residues from palm oil mills in Thailand: an overview on quantity and potential usage. Biomass Bioenergy 11(5): 387-395.

27. Rachini, A., Le Troedec, M., Peyratout, C. \& Smith, A. 2012. Chemical modification of hemp fibers by silane coupling agents. Journal of Applied Polymer Science 123(1): 601-610. 
28. Rowell, R. M., Schultz, T. P. \& Narayan, R. 1992. Emerging technologies for materials and chemicals from biomass Ed.: ACS Publications.

29. Sheltami, R. M., Abdullah, I., Ahmad, I., Dufresne, A. \& Kargarzadeh, H. 2012. Extraction of cellulose nanocrystals from mengkuang leaves (Pandanus tectorius). Carbohydrate Polymers 88(2): 772-779.

30. Singh, R. P., Ibrahim, M. H., Esa, N. \& Illiyana, M. S. 2010. Composting of waste from palm oil mill: a sustainable waste management practice. Reviews in Environmental Science and Biotechnology 9(4): 331344.

31. Thakur, V. K., Thakur, M. K., \& Gupta, R. K. 2013b. Synthesis of lignocellulosic polymer with improved chemical resistance through free radical polymerization. International Journal of Biological Macromolecules 61: 121-126.

32. Thakur, V.K., Thakur, M.K., Gupta, R.K., 2014. Review: Raw natural fiber-based polymer composites. Int. J. Polym. Anal. Charact. 19: 256-271.

33. Thakur, M. K., Gupta, R. K. \& Thakur, V. K. 2014. Surface modification of cellulose using silane coupling agent. Carbohydrate Polymers 111: 849-855.

34. Tserki, V., Zafeiropoulos, N., Simon, F. \& Panayiotou, C. 2005. A study of the effect of acetylation and propionylation surface treatments on natural fibres. Composites Part A: applied science and manufacturing 36(8): 1110-1118.

35. Walia, Y. K., Kishore, K., Vasu, D. \& Gupta, D. 2009. Physico-chemical analysis of Ceiba pentandra (Kapok). Inter. J. Theor. Appl. Sci 1(2): 15-18.

36. Wang, Y., Tong, B., Hou, S., Li, M. \& Shen, C. 2011. Transcrystallization behavior at the poly (lactic acid)/sisal fibre biocomposite interface. Composites Part A: Applied Science and Manufacturing 42(1): 66-74.

37. Wang, J., Zheng, Y. \& Wang, A. 2012. Effect of kapok fiber treated with various solvents on oil absorbency. Industrial Crops and Products 40: 178-184.

38. Yu, C.-H., Huang, C.-H. \& Tan, C.-S. 2012. A review of CO2 capture by absorption and adsorption. Aerosol Air Qual. Res 12: 745-769

39. Zhao, H., Ma, Y., Tang, J., Hu, J. \& Liu, H. 2011. Influence of the solvent properties on MCM-41 surface modification of aminosilanes. Journal of solution chemistry 40(4): 740-749. 